\title{
Dental Status of Firefighters of Rio de Janeiro State and Comparison with Brazilian Oral Health Surveys
}

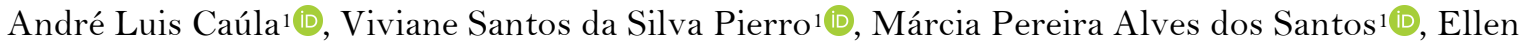 \\ Rose Bundzman ${ }^{\circledR}$, José dos Santos Branco Júnior ${ }^{1}$, Luiz Henrique Schwartz Tavares ${ }^{1}(1)$
}

${ }^{1}$ Military Fire Brigade of the State of Rio de Janeiro, Rio de Janeiro, RJ, Brazil.

Correspondence: André Luis Caúla, Av. Prefeito Silvio Picanço 1495, Charitas, Niteroi, RJ, Brazil. 24380-030. E-mail: andrecaula@gmail.com

Academic Editor: Wilton Wilney Nascimento Padilha

Received: 04 March 2020 / Review: 08 September 2020 / Accepted: 16 February 2021

\begin{tabular}{l} 
How to cite: Caúla AL, Pierro VSS, Santos MPA, Bundzman ER, Branco Júnior JS, Tavares LHS. Dental status of \\
firefighters of Rio de Janeiro state and comparison with Brazilian oral health surveys. Pesqui Bras Odontopediatria Clín \\
Integr. 202 1; 21 :e0038. https://doi.org/10.1590/pboci.2021.105 \\
\hline
\end{tabular}

\begin{abstract}
Objective: This cross-sectional study aimed to assess clinical dental status in military firefighters of Rio de Janeiro State and compare data with Brazilian National and Regional oral health surveys. Material and Methods: A sample of 926 military firefighters was examined using the visible biofilm index, the DMFT index and the Community Periodontal Index (CPI). Clinical exams were performed by 15 trained dentists. The Kruskal-Wallis test and Mann-Whitney test with Bonferroni correction were used. Results: Higher biofilm accumulation was associated with increased age. The mean DMFT index for the whole sample of this study was $12.74( \pm 7.03)$, and the 'filled' component was the most prevalent $(69.9 \%)$, whereas the 'decayed' and 'missing' components were, respectively, $8.4 \%$ and $21.7 \%$. There was a higher prevalence of periodontal diseases with increasing age, ranging from $57.1 \%$ in firefighters of 34 years or less to $70.5 \%$ in the ones between 35 and 44 years old and $75.4 \%$ in participants at age 45 years or older. Clinical dental status of the military firefighters who belonged to the age group 35-44 was better than the one observed for the Brazilian population at the same age range. However, pathological conditions that can be solved with health promotion strategies associated with dental procedures of low complexity still persist. Conclusion: These results suggest that the availability of dental health care services itself does not represent the most effective approach to the oral health problems found in the studied population.
\end{abstract}

Keywords: Health Surveys; Oral Health; Firefighters; Dental Caries; Periodontal Diseases. 


\section{Introduction}

Firefighters are responsible for saving lives and protecting property. Their mission put them into high-risk situations, which require a high level of physical and mental abilities for carrying out their activities [1]. Some studies have suggested that subjects with poor oral health may show decreased physical performance [2-4] and have a negative impact on general health and well-being [2,5-7], which could impair some firefighters' activities.

The main oral diseases affecting adults are caries and periodontal diseases [8]. The outcome for both diseases, when untreated, may be tooth loss, reduced masticatory function, poor nutritional status, low selfesteem, and poor quality of life, as well as negative impacts on general health [4-7,9,10].

Epidemiological surveys to determine the oral health status and treatment needs of communities and populations are important for the surveillance of disease patterns [11]. In addition to epidemiological information, surveys also allow health planners and decision-makers to assess the effectiveness of the services being provided and to plan or modify oral health services and training programmes as needed.

The most recent Brazilian National Oral Health Survey (SB Brazil-2010) showed increased dental caries prevalence according to increasing age, using the DMFT index as the measure for caries experience [12]. The mean percentage of caries-free subjects $($ DMFT $=0$ ) at age 12 was $43.5 \%$, decreasing to $23.9 \%$ between 15 and 19 years of age, followed by a drastic reduction in adult life (35-44 years) and in the elderly (65-74 years), respectively $0.9 \%$ and $0.2 \%$ [12]. The results from this survey also revealed a prevalence of gingivitis of $33.8 \%$ and $45.8 \%$, and of periodontitis of $10.5 \%$ and $34.6 \%$, respectively, for age groups $15-19$ and 35-44 [12]. Also, this survey showed the prevalence of partial or total edentulism significantly increased with age (for example, $1.5 \%, 32.3 \%$, and $90.5 \%$ for subjects aged 15 to 19,35 to 44, and 65 to 74 years, respectively), reducing the number of teeth examined, which resulted in a lower prevalence of the periodontal diseases [12].

Although current evidence suggests that firefighters are at increased risk for heart attacks on duty [13,14], cancer [15], and occupational injuries [16], and despite the increased research on oral health conditions worldwide, researches on the prevalence of dental caries and periodontal disease in firefighters are still lacking. Considering that firefighters usually have an unpredictable daily routine when at work, being available for immediate response to emergencies, they could be more susceptible to biofilm-dependent oral diseases. Accordingly, an oral health survey of the military firefighters who belong to the Fire Department of the Rio de Janeiro State (CBMERJ) had never been performed until this study started. CBMERJ is a statewide military governmental organization that has its own Health Care System, which provides medical and dental care privately for the military firefighters and their family dependents with resources from a monthly fee charged from their income. Its Dental Health Care Units are composed of 40 Dental Clinics and Decentralized Dental Care Units, geographically spread across the metropolitan and interior regions of Rio de Janeiro State.

This study aimed to assess clinical dental status in military firefighters of Rio de Janeiro State and compare these findings with the results from oral health surveys performed in Brazil.

\section{Material and Methods}

\section{Study Design}

The present study reports a cross-sectional epidemiological survey performed between September 2009 and November 2012. To evaluate the oral health status of military firefighters of CBMERJ, the Oral Health Division (DGO) carried out the "Smile Firefighter Project", which included oral health educational activities, screening for dental treatment needs and an epidemiological survey of the oral health conditions of 
this population. This epidemiological survey named the Oral Health Survey of Fire Department of the Rio de Janeiro State (SB CBMERJ-2012) was the first study of this nature carried out in CBMERJ.

\section{Study Population}

The studied population included military firefighters from enlisted personnel rank of the CBMERJ (Brazil), from both sexes, who agreed to participate in the survey. All study participants were informed about the aims of the research and signed the informed consent form. Subjects who needed dental care treatment were informed of their oral health status and referred to a dental health care unit in CBMERJ. The study protocol was approved by the Research Ethics Committee of the Souza Marques School of Medicine (Protocol number 2.978.041).

\section{Sample Size}

Sample size calculation was performed using the Open Source Statistics for Public Health (OpenEpi version 2.3.1 program), considering a total population of 14,504 military firefighters in September 2009. Data of dental caries and periodontal diseases prevalences in the Brazilian adult population aged 35-44 years, respectively, 99.48\% and 78.06\% (SB Brazil-2003) [17], were used at a significance level of 5\% and a design effect of 1.0. This procedure yielded a sample size of at least 259 subjects. However, the number of firefighters who volunteered for this survey reached 926 subjects. The only exclusion criterion was a refusal to participate in the survey.

\section{Clinical Examinations}

All the participants were examined concerning dental caries and periodontal diseases, using criteria recommended by WHO for oral health surveys [11]. DMFT index was used to assess the dental condition (crown only) in relation to the current and previous experience of dental caries, and the Community Periodontal Index (CPI) was used for periodontal evaluation [11]. The presence of dental biofilm was assessed by visual examination, according to the dichotomous Visible Plaque Index proposed by Ainamo and Bay [18], which was modified in the present study to record the absence or presence of visible biofilm by sextants.

Clinical exams were performed by 15 trained dentists. The inter-examiner agreement was performed with another sample group, specifically selected for calibration purposes, and the obtained weighted Kappa index was 0.87 for the DMFT index, which is considered very good [19].

A total of 40 operational units of CBMERJ were randomly selected to participate in this study. Firefighters from those units were invited to participate in the survey. Clinical exams were performed in a dental office installed in a trailer from the Mobile Dental Care Service of CBMERJ, according to universal infection control measures. Oral examinations were performed under artificial light, with sterilized plane mouth mirrors and CPI standard probes. Each examiner was assisted by a trained assistant responsible for registering the index scores in an appropriate form that was also used to register participants' age, sex, and identification number.

\section{Comparative Analysis}

This study sample was distributed among three age groups (subjects aged 34 years or less, 35 to 44 years and 45 years or more) to allow comparability with the studies that follow WHO recommendation, in which the age group 35-44 is used as a reference to evaluate oral health conditions in adult populations [12]. 
Results from the present study for the age group 35-44 were compared to the ones for the same age group, from Oral Health Surveys performed in Brazil (SB Brazil-2010 and SB São Paulo-2015) [12,20]. To allow comparisons among the studies, it was necessary to make some adjustments in the original data from the two mentioned surveys. Concerning dental caries, both surveys [12,20] showed DMFT results, including a category of "carious filled teeth". This category was, therefore, included in the "decayed teeth" category for comparative purposes. Data regarding dental caries in Rio de Janeiro state were obtained from SB-Brazil 2010 $[12]$.

Adjustments were also made for periodontal status data, from which 35-44-year-old subjects who had a score "X" (excluded) in all sextants (less than two teeth present per sextant) were excluded from the comparative sample of both surveys $[12,20]$ and the frequency distribution of CPI scores was recalculated according to the new sample size obtained.

\section{Statistical Analysis}

Statistical data analysis was performed by using the SPSS 21.0 program (SPSS Inc., Chicago, IL) at a significance level of 5\%. The non-parametric Kruskal-Wallis test was used to check the association between age groups and numerical variables, such as the DMFT index and the mean number of sextants affected by the different periodontal conditions verified by the CPI. In cases where a statistically significant difference was found among the three groups, the Mann-Whitney test with Bonferroni correction was applied, resulting in a significance level of $1.7 \%$.

Chi-square test was used to verify the association between age groups and the different CPI scores observed for the studied sample, as well as between those groups and the presence of visible biofilm in at least one of the examined sextants.

\section{Results}

This study sample consisted of $890(96.1 \%)$ men and only 36 (3.9\%) women, and the mean age was 37.3 years $( \pm 8.01)$, ranging from 19 to 68 years, distributed as follows: $\leq 34$ years $(36.7 \%), 35-44$ years $(44.0 \%)$ and $\geq 45$ years $(19.3 \%)$.

Prevalence of visible biofilm in at least one sextant was $43.5 \%, 52.6 \%$, and $61.5 \%$, respectively, in participants of 34 years or less, in the ones between 35 and 44 years old and at age 45 years or older. The studied population showed, therefore, higher biofilm accumulation among the age groups as age increased $(\mathrm{p}<0.001)$

The mean DMFT index for the whole sample of this study was 12.74 ( \pm 7.03) and its caries prevalence was $96 \%$, considering that caries-free subjects (DMFT $=0$ ) corresponded to $4 \%$ of the studied population. Regarding the composition of the DMFT index, the 'filled component' was the most prevalent in this sample (69.9\%), while the 'decayed' and 'missing components' accounted, respectively, for $8.4 \%$ and $21.7 \%$ of the index. The sample's distribution according to age group, DMFT index and the proportion of its components is presented in Table 1 .

The periodontal status and its distribution in the study sample according to the CPI index are presented by age groups in Tables 2 and 3. The number of subjects with periodontal health progressively declined among the age groups as age increased, showing a prevalence of periodontitis ranging from $57.1 \%$ to $75.4 \%$, respectively, in subjects of 34 years or less and at age 45 years or older $(\mathrm{p}<0.001)$. However, bleeding on probing and dental calculus were more prevalent than periodontal pockets in the studied population, 
corresponding to 23.9 and $28.7 \%$ of the affected subjects, respectively. The prevalence of shallow (15.7\%) and deep $(3.1 \%)$ periodontal pockets was more evident in the $35-44-y e a r-o l d$ age group $(\mathrm{p}<0.001)$. The mean number of healthy sextants decreased gradually among the age groups as age increased $(p<0.017)$, and the presence of periodontal pockets was evident from the age of 35 years, with a mean number of sextants affected by periodontitis statistically higher in the 35-44-year-old group when compared to the younger group ( $\leq 34$ years) $(\mathrm{p}<0.017)$.

Table 1. Distribution of DMFT index and its components by age group.

\begin{tabular}{|c|c|c|c|c|c|c|c|c|c|}
\hline $\begin{array}{c}\text { Age } \\
\text { Group } \\
\text { (Years) }\end{array}$ & $\mathbf{N}$ & Statistics & Decayed & Missing & Filled & DMFT & $\begin{array}{c}\text { Number of } \\
\text { Healthy } \\
\text { Teeth per } \\
\text { Person }\end{array}$ & $\begin{array}{c}\text { Total } \\
\text { Number of } \\
\text { Teeth per } \\
\text { Person }\end{array}$ & $\begin{array}{c}\text { DMFT } \\
\text { Zero }\end{array}$ \\
\hline \multirow[t]{3}{*}{$\leq 34$} & 340 & Mean & $0.62^{\mathrm{a}}$ & $0.73^{\mathrm{a}}$ & $7.02^{\mathrm{a}}$ & $8.37^{a}$ & $21.69^{\mathrm{a}}$ & $29.47^{\mathrm{a}}$ & - \\
\hline & & $\mathrm{SD}$ & 1.14 & 1.41 & 5.17 & 5.90 & 6.15 & 2.33 & - \\
\hline & & $\%$ & 7.41 & 8.72 & 83.87 & 100.00 & 73.60 & 100.0 & 10.30 \\
\hline \multirow[t]{3}{*}{$35-44$} & 407 & Mean & $1.33^{\mathrm{b}}$ & $2.77^{\mathrm{b}}$ & $10.21^{\mathrm{b}}$ & $14.31^{\mathrm{b}}$ & $16.03^{\mathrm{b}}$ & $27.65^{\mathrm{b}}$ & - \\
\hline & & $\mathrm{SD}$ & 2.12 & 3.30 & 5.28 & 6.05 & 5.94 & 3.53 & - \\
\hline & & $\%$ & 9.29 & 19.36 & 71.35 & 100.00 & 57.97 & 100.0 & 0.50 \\
\hline \multirow[t]{3}{*}{$\geq 45$} & 179 & Mean & $1.35^{\mathrm{b}}$ & $6.60^{c}$ & $9.5 \mathrm{O}^{\mathrm{b}}$ & $17.45^{\mathrm{c}}$ & $12.79^{\mathrm{c}}$ & $23.67^{\mathrm{c}}$ & - \\
\hline & & $\mathrm{SD}$ & 2.04 & 5.94 & 5.32 & 6.54 & 6.18 & 5.99 & - \\
\hline & & $\%$ & 7.74 & 37.82 & 54.44 & 100.00 & 54.03 & 100.0 & 0.00 \\
\hline \multirow[t]{3}{*}{ Total } & 926 & Mean & 1.07 & 2.76 & 8.90 & 12.74 & 17.48 & 27.55 & - \\
\hline & & $\mathrm{SD}$ & 1.84 & 4.08 & 5.44 & 7.03 & 6.96 & 4.32 & - \\
\hline & & $\%$ & 8.40 & 21.70 & 69.90 & 100.00 & 63.45 & 100.0 & 4.00 \\
\hline
\end{tabular}

Distinct superscript letters in the same column indicate statistical significance (p<0.05, Kruskal-Wallis test; <0.017, Mann-Whitney test with Bonferroni correction).

Table 2. Prevalence of periodontal diseases based on the highest CPI score per person by age group.

\begin{tabular}{|c|c|c|c|c|c|c|}
\hline \multirow{3}{*}{ Age Group (Years) } & \multirow[t]{3}{*}{$\mathbf{N}$} & \multicolumn{5}{|c|}{ \% Subjects According to the Highest CPI Score* } \\
\hline & & 0 & 1 & $2^{0}$ & 3 & 4 \\
\hline & & Healthy & Bleeding & Calculus & Shallow Pockets & Deep Pockets \\
\hline$\leq 34$ & 210 & 42.9 & 23.8 & 27.1 & 6.2 & 0.0 \\
\hline $35-44$ & 261 & 29.5 & 24.5 & 27.2 & 15.7 & 3.1 \\
\hline$\geq 45$ & 114 & 24.6 & 22.8 & 35.1 & 15.8 & 1.8 \\
\hline Total & 585 & 33.3 & 23.9 & 28.7 & 12.3 & 1.7 \\
\hline
\end{tabular}

*p $<0.0001$, Pearson's Chi-square test.

Table 3. Mean number of sextants with different CPI scores by age group.

\begin{tabular}{|c|c|c|c|c|c|c|c|c|}
\hline \multirow{3}{*}{$\begin{array}{c}\text { Age } \\
\text { Group } \\
\text { (Years) }\end{array}$} & \multirow{3}{*}{$\mathbf{N}$} & \multirow{3}{*}{$\begin{array}{c}\text { Mean } \\
\text { Number of } \\
\text { Teeth per } \\
\text { Person (SD) }\end{array}$} & \multicolumn{6}{|c|}{ Mean Number of Sextants by CPI Score (SD)* } \\
\hline & & & $\mathrm{O}$ & 1 & 2 & 3 & 4 & X \\
\hline & & & Healthy & Bleeding & Calculus & $\begin{array}{l}\text { Shallow } \\
\text { Pockets }\end{array}$ & $\begin{array}{c}\text { Deep } \\
\text { Pockets }\end{array}$ & Excluded \\
\hline$\leq 34$ & 210 & $29.54^{\mathrm{a}}(2.04)$ & $4.59^{\mathrm{a}}(1.68)$ & $0.88^{\mathrm{a}}(1.33)$ & $0.42^{\mathrm{a}}(0.85)$ & $0.10^{\mathrm{a}}(0.39)$ & $0.00^{\mathrm{a}}(0.00)$ & $0.02^{\mathrm{a}}(0.17)$ \\
\hline $35-44$ & 261 & $27.72^{\mathrm{b}}(3.43)$ & $3.93^{b}(1.90)$ & $0.90^{\mathrm{a}}(1.28)$ & $0.62^{\mathrm{a}, \mathrm{b}}(1.11)$ & $0.29^{b}(0.71)$ & $0.03^{\mathrm{b}}(0.20)$ & $0.19^{b}(0.68)$ \\
\hline$\geq 45$ & 114 & $24.11^{\mathrm{c}}(5.98)$ & $3.19^{\mathrm{c}}(1.96)$ & $1.06^{\mathrm{a}}(1.40)$ & $0.71^{b}(1.04)$ & $0.32^{\mathrm{b}}(0.78)$ & $0.04^{\mathrm{a}, \mathrm{b}}(0.30)$ & $0.66^{\mathrm{c}}(1.32)$ \\
\hline Total & 585 & $27.67(4.16)$ & $4.02(1.90)$ & $0.92(1.32)$ & $0.57(1.01)$ & $0.22(0.64)$ & $0.02(0.19)$ & $0.22(0.78)$ \\
\hline
\end{tabular}

Distinct superscript letters in the same column indicate statistical significance $(\mathrm{p}<0.05$, Kruskal-Wallis test; $\mathrm{p}<0.017$, Mann-Whitney test with Bonferroni correction).

Comparative analyses between the present study and SB Brazil-2010 [12], and SB São Paulo-2015 [20], with regard to dental caries and periodontal status of the 35-44-year-old groups, are shown in Figures 1 and 2. 


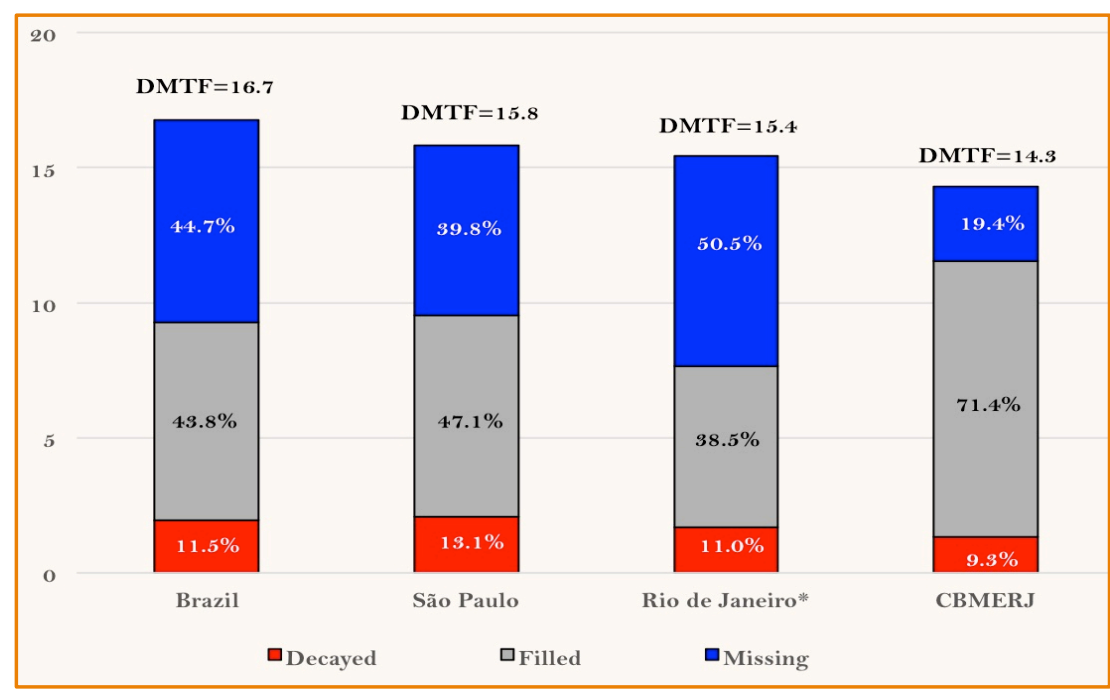

*Data regarding dental caries in Rio de Janeiro state were obtained from SB-Brazil 2010 [12].

Figure 1. Dental caries experience (DMFT) in 35-44-year-old subjects from SB CBMERJ-2012, SB Brazil-2010 [12] and SB São Paulo-2015 [20].

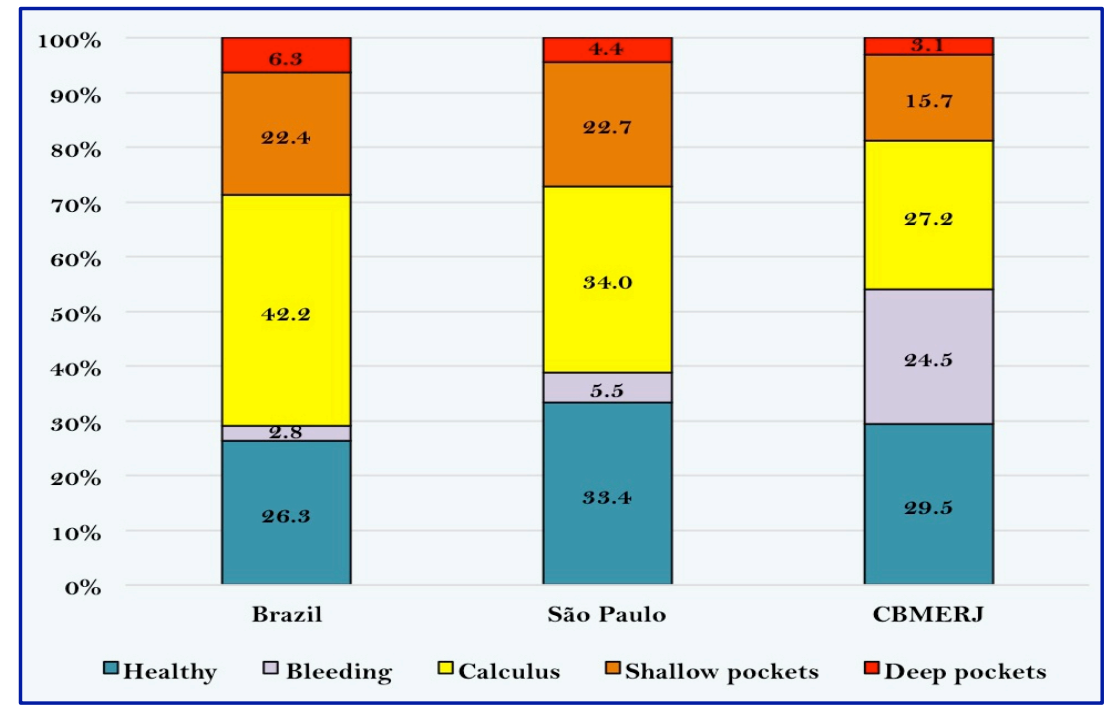

Figure 2. Periodontal disease prevalence among 35-44-year-old subjects from SB CBMERJ-2012, SB Brazil-2010 [12] and SB São Paulo-2015 [20].

\section{Discussion}

This oral health survey assessed the prevalence of dental caries and periodontal diseases in a representative sample of Rio de Janeiro State military firefighters. These two diseases are common oral diseases that affect all populations, varying only in prevalence and severity. Therefore, those pathologies need adequate strategic control actions according to the epidemiological profile of each affected population. Epidemiological oral health surveys provide a secure basis for assessing oral health status and treatment needs [21]. In addition, standardized methods to measure disease levels in a population allow for comparisons among different realities, either at the national or global levels.

In the present study, the percentage of caries-free subjects (DMFT zero) at the age group $\leq 34$ years was $10.3 \%$, and almost none of the participants aging 35 years old or more were caries-free. Despite the 
limitations of this cross-sectional study, the mean DMFT increased whenever subjects from older age groups were examined and age was statistically associated with DMFT. This finding may not be surprising because caries is cumulative and chronic in nature [22]. Dental caries experience in firefighters between 35 and 44 years of age $(\mathrm{DMFT}=14.3)$ was classified as high, based on the severity scale proposed by WHO, which establishes DMFT above 13.9 as high caries experience in this index age group [21]. However, Figure 1 shows that the mean DMFT in firefighters from this age group was the lowest when compared to data from large oral surveys carried out in samples from the Brazilian population and from the States of São Paulo and Rio de Janeiro (mean DMFT = 16.75, 15.84 and 15.45, respectively) [12,20].

The DMFT index measures both past (missing and filled teeth) and present (decayed teeth) dental caries experience. Therefore, it is necessary to evaluate each one of its components separately to better define the dental caries profile of the studied population. The high number of restored teeth ('filled') and its increase along the age groups observed in CBMERJ firefighters suggest that the professional approach to dental caries management is still based on the operative treatment of diagnosed carious lesions without the adoption of strategies to prevent the development of new lesions. The fact that the DMFT is a cumulative index does not mean it cannot remain stable over time, indicating that no further caries has developed [22]. Operative intervention starts a cycle of re-restoration that progressively leads to more lost tooth structure and can often culminate in tooth loss [23,24]. This fact was demonstrated in this study by the progressive increase in the mean number of lost teeth due to caries along with the studied age groups and by the consequent decrease in the total number of teeth present per subject.

The Brazilian National Health System is a universal health system that allows access to oral care for all age groups, from early childhood to seniors, without direct costs to the population [25]. The quality of public dental care in Brazil has improved considerably since oral health care was incorporated into the Unified Health System (SUS, acronym in Portuguese) in 2004 [26,27]. The National Oral Health Policy sets out a national protocol that includes a range of basic oral healthcare procedures (preventive, restorative/prosthetic, surgical, endodontic, and monitoring of oral health conditions) considered necessary for the epidemiological need of the Brazilian population. However, studies have shown inequalities in the access and utilization of public dental health services to the overall population, as well as a limited number of complex dental procedures in practice [25,28]. In contrast, the Oral Health Care System in CBMERJ promotes greater access to Dental Health Care units and offers a wide range of oral healthcare procedures to firefighters and their family dependents, which could explain the difference in the prevalence of 'decayed' and 'filled' teeth among these populations.

Caries levels increase with increasing age and continue to be a major problem in adults [22]. Lifetime experience of dental caries in adults approaches 100\% [29]. Availability of community-based and individual methods of fluoride could have influenced dental caries prevalence in adults (period effects). In Brazil, fluoridation of water supplies has been mandatory since 1975, but its implementation was progressive mainly after the mid-1980s. Also, fluoridated toothpaste reached the market on a large-scale basis in 1990 [30]. Thus, adults aging 35 years old or more at the time of the present study were born in the 80's or earlier, when there was no availability of fluoridated tap water and fluoridated toothpastes, as well as before the previously mentioned changes on public oral health policies. Those facts could explain, in part, the high dental caries experience in the sample of firefighters aging 35 years old or more. However, a study that aimed to assess the relative influences of age, period, and cohort effects on trends in caries experience of permanent teeth in 4 
different populations (all of them from developed countries), showed that age effects on caries experience in permanent teeth, as assessed by the DMFT index, were stronger than those of period and cohort effects [22].

The periodontal evaluation of the firefighters examined in this study was performed using the CPI, whose data presentation is frequently based on the percentage of subjects according to the highest score recorded for each person, indicating a prevalence of periodontal conditions [31]. In addition, the mean number of sextants by CPI score was also presented as a measure of severity or of extent of the periodontal disease [31]. In the present study, the percentage of subjects who showed healthy periodontal tissues was significantly higher in the age group of 34 years or less $(42.9 \%)$ when compared to the 35-44-year-old group and to those at age 45 years or older $(29.5 \%$ and $24.6 \%$, respectively). However, as shown in Table 3 , the mean number of healthy sextants $(\mathrm{CPI}=0)$ was three or four times greater than the mean number of sextants showing each of the other periodontal conditions. This may represent a limitation of the CPI, which is based on a partial periodontal examination and on a hierarchical relationship wherein the highest clinical disease indicator is scored for each examined sextant. Thus, once the worst periodontal condition observed in at least one of the subjects' sextants is used as their score at the subject level, healthy sextants are, consequently, discarded and there is an overestimation of the actual disease rates.

Comparisons among this study and the Oral Health Surveys SB Brazil-2010 [12] and SB São Paulo2015 [20] (Figure 2) demonstrate that the 35-44-year-old subjects examined in the three epidemiological surveys showed high periodontal disease prevalence (around 70\%). The sample of this study also presented a percentage of subjects showing healthy periodontal tissues slightly lower than that observed in the SB-São Paulo 2015 [20], which was a surprising result once the examined firefighters comprise an institutionalized sample that, in theory, has greater access to oral health care than São Paulo's representative population sample. It is worthy to mention, however, that the most frequent periodontal conditions shown by firefighters were bleeding on probing and dental calculus (51.7\%), both reversible with adequate treatment. On the other hand, firefighters showed lower periodontitis prevalence (18.8\%) than Brazilian (28.7\%) and São Paulo state (27.1\%) populations. In addition, the percentage of 35-44-year-old subjects with all sextants excluded (Score "X") were 32.3\% and 3.28\%, respectively for the Oral Health Surveys SB Brazil-2010 [12] and SB São Paulo-2015 [20], while none of the firefighters from this survey were totally edentulous or had all sextants excluded.

Traditional models of oral health care have been based on the repair and restoration of tissues after the onset of the disease. Thus, diagnoses have been formulated with invasive therapeutic interventions in mind, based on the operative treatment philosophy for oral care. A preventive approach requires early diagnosis, health education and patients' motivation to change their behavior, as well as greater patients' responsibility for their own health under the guidance and support of the professional staff [32].

\section{Conclusion}

The prevalence and severity of oral conditions, their distribution in the population, and projected changes over time should be among the primary considerations for dental health care services planning. The current study showed significant data on the prevalence of dental caries and periodontal diseases in military firefighters of Rio de Janeiro State. Although the prevalence of these two oral diseases has been high in the studied population, only a small percentage of firefighters showed untreated caries or severe forms of periodontal disease. These results suggest that firefighters have better oral health conditions than the Brazilian population, considering the age group used as a reference to evaluate oral health conditions in adult populations. 
Nevertheless, pathological conditions that can be solved with health promotion measures and low complexity procedures still persist. This situation was noticed while analyzing the small number of subjects who needed restorative treatment and the significant percentage of subjects who require low complexity periodontal treatment. These results suggest that the availability of dental health care services itself does not represent the most effective approach to the oral health problems found in the examined firefighters. Therefore, it is suggested that, in order to achieve an improvement in the prevalence of dental caries and periodontal diseases in the studied population, investments be made in the reorganization of the oral health care model, with emphasis on health promotion measures and whole care. In addition, dentists should change their attitude towards their patients, spending more time on oral health education activities. There is an important need for greater firefighters' awareness of oral diseases, their etiological factors, prevention and control mechanisms once the prime investments in the operative treatment alone has not proved to be enough in the control of the studied oral diseases.

\section{Authors' Contributions}

\begin{tabular}{|c|c|c|}
\hline ALC & (D) https://orcid.org/0000-0003-1520-8827 & $\begin{array}{l}\text { Conceptualization, Methodology, Formal Analysis, Investigation, Writing - Original Draft, } \\
\text { Writing - Review and Editing and Project Administration. }\end{array}$ \\
\hline VSSP & (D) https://orcid.org/0000-0003-4733-7930 & $\begin{array}{l}\text { Methodology, Formal Analysis, Investigation, Writing - Original Draft and Writing - Review } \\
\text { and Editing. }\end{array}$ \\
\hline MPAS & (iD) https://orcid.org/0000-0003-0349-8521 & Conceptualization, Methodology, Investigation and Writing - Review and Editing. \\
\hline ERB & (iD) https://orcid.org/0000-0002-5584-0563 & Conceptualization, Methodology and Writing - Review and Editing. \\
\hline JSBJ & (iD) https://orcid.org/0000-0002-7586-9881 & Writing - Review and Editing and Project Administration. \\
\hline LHST & (iD) https://orcid.org/0000-0002-9804-5893 & Resources, Writing - Review and Editing, Supervision and Project Administration. \\
\hline
\end{tabular}

\section{Financial Support}

None.

\section{Conflict of Interest}

The authors declare no conflicts of interest.

\section{Data Availability}

The data used to support the findings of this study can be made available upon request to the corresponding author.

\section{Acknowledgments}

The authors thank Prof. Ronir Raggio Luiz for assistance with statistical analysis.

\section{References}

[1] Jahnke SA, Poston WS, Jitnarin N, Haddock CK. Health concerns of the U.S. fire service: perspectives from the firehouse. Am J Health Promot 2012; 27(2):111-8. https://doi.org/10.4278/ajhp.110311-QUAL-109

[2] Needleman I, Ashley P, Petrie A, Fortune F, Turner W, Jones J, et al. Oral health and impact on performance of athletes participating in the London 2012 Olympic Games: a cross-sectional study. Br J Sports Med 2013; 47(16):1054-8. https://doi.org/10.1136/bjsports-2013-092891

[3] Gay-Escoda C, Vieira-Duarte-Pereira DM, Ardèvol J, Pruna R, Fernandez J, Valmaseda-Castellón E. Study of the effect of oral health on physical condition of professional soccer players of the Football Club Barcelona. Med Oral Patol Oral Cir Bucal 2011; 16(3):436-9. https://doi.org/10.4317/medoral.16.e436

[4] Oliveira JA, Hoppe CB, Gomes MS, Grecca FS, Haas AN. Periodontal disease as a risk indicator for poor physical fitness: a cross-sectional observational study. J Periodontol 2015; 86(1):44-52. https://doi.org/10.1902/jop.2014.140270

[5] Hoppe CB, Oliveira JAP, Grecca FS, Haas AN, Gomes MS. Association between chronic oral inflammatory burden and physical fitness in males: a cross-sectional observational study. Int Endod J 2017; 50(8):740-9. https://doi.org/10.1111/iej.12686 
[6] Caúla AL, Lira-Junior R, Tinoco EM, Fischer RG. The effect of periodontal therapy on cardiovascular risk markers: a 6-month randomized clinical trial. J Clin Periodontol 2014; 41(9):875-82. https://doi.org/10.1111/jcpe.12290

[7] Caúla AL, Lira-Junior R, Tinoco EM, Fischer RG. Serum creatinine and alkaline phosphatase levels are associated with severe chronic periodontitis. J Periodontal Res 2015; 50(6):793-7. https://doi.org/10.1111/jre.12266

[8] Kassebaum NJ, Smith AGC, Bernabé E, Fleming TD, Reynolds AE, Vos T, et al. Global, regional, and national prevalence, incidence, and disability-adjusted life years for oral conditions for 195 countries, 1990-2015: a systematic analysis for the global burden of diseases, injuries, and risk factors. J Dent Res 2017; 96(4):380-7. https://doi.org/10.1177/0022034517693566

[9] Chapple IL, Bouchard P, Cagetti MG, Campus G, Carra MC, Cocco F, et al. Interaction of lifestyle, behaviour or systemic diseases with dental caries and periodontal diseases: consensus report of group 2 of the joint EFP/ORCA workshop on the boundaries between caries and periodontal diseases. J Clin Periodontol 2017; 44:39-51. https://doi.org/10.1111/jcpe.12685

[10] Spanemberg JC, Cardoso JA, Slob EMGB, López-López J. Quality of life related to oral health and its impact in adults. J Stomatol Oral Maxillofac Surg 2019; 120(3):234-9. https://doi.org/10.1016/j.jormas.2019.02.004

[11] World Health Organization. Oral Health Surveys: Basic Methods. $4^{\text {th }}$. ed. Geneva: WHO; 1997.

[12] Brasil. Ministério da Saúde. SB Brasil 2010: Pesquisa Nacional de Saúde Bucal: resultados principais. Brasília:

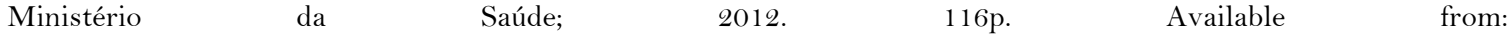
http://bvsms.saude.gov.br/bvs/publicacoes/pesquisa_nacional_saude_bucal.pdf. [Accessed on February 10, 2018]. [In Portuguese].

[13] Kales SN, Soteriades ES, Christophi CA, Christiani DC. Emergency duties and deaths from heart disease among firefighters in the United States. N Engl J Med 2007; 356(12):1207-15. https://doi.org/10.1016/10.1056/NEJMoa060357

[14] Soteriades ES, Smith DL, Tsismenakis AJ, Baur DM, Kales SN. Cardiovascular disease in US firefighters: a systematic review. Cardiol Rev 2011; 19(4):202-15. https://doi.org/10.1097/CRD.obo13e318215c105

[15] LeMasters GK, Genaidy AM, Succop P, Deddens J, Sobeih T, Barriera-Viruet H, et al. Cancer risk among firefighters: a review and meta- analysis of 32 studies. J Occup Environ Med 2006; 48(11):1189-1202. https://doi.org/10.1097/01.jom.0000246229.68697.90

[16] Frost DM, Beach TA, Crosby I, McGill SM. Firefighter injuries are not just a fireground problem. Work 2015; 52(4):835-42. https://doi.org/10.3233/WOR-152111

[17] Brasil. Ministério da Saúde. Secretaria de Atenção à Saúde. Departamento de Atenção Básica. Projeto SB Brasil 2003: condições de saúde bucal da população brasileira 2002-2003: resultados parciais. Brasília: Ministério da Saúde; 2004. Available from: http://bvsms.saude.gov.br/bvs/publicacoes/condicoes_saude_bucal.pdf. [Accessed on April 10, 2017]. [In Portuguese].

[18] Ainamo J, Bay I. Problems and proposals for recording gingivitis and plaque. Int Dent J 1975; 25(4):229-35.

[19] Byrt T. How good is that agreement? Epidemiology 1996; 7(5):561. https://doi.org/10.1097/00001648-199609000-00030

[20] Frias AC, Pereira AC, Vieira V. Pesquisa estadual de saúde bucal: Relatório final. Águas de São Pedro: Livronovo, 2016. Available from: https://w2.fop.unicamp.br/sbsp2015/down/ebook_relatorio_SBSP_2015.pdf. [Accessed on August 19, 2019]. [In Portuguese].

[21] Petersen PE, Baez RJ, World Health Organization. Oral Health Surveys: Basic Methods. 5th ed. Geneve: WHO; 2013.

[22] Bernabé E, Sheiham A. Age, period and cohort trends in caries of permanent teeth in four developed countries. Am J Public Health 2014; 104(7):115-2 1. https://doi.org/10.2105/AJPH.2014.301869

[23] Simonsen RJ. New materials on the horizon. J Am Dent Assoc 1991; 122(7):24-31. https://doi.org/10.14219/jada.archive.1991.0217

[24] Dennison JB, Hamilton JC. Treatment decisions and conservation of tooth structure. Dent Clin North Am 2005; 49(4):825-45. https://doi.org/10.1016/j.cden.2005.05.007

[25] Mendes SR, Martins RC, Matta-Machado ATGM, Mattos GCM, Gallagher JE, Abreu MHNG. Dental procedures in primary health care of the Brazilian National Health System. Int J Environ Res Public Health 2017; 14(12):1480. https://doi.org/10.3390/ijerph 14121480

[26] Paim J, Travassos C, Almeida C, Bahia L, Macinko J. The Brazilian health system: history, advances, and challenges. Lancet 2011; 377(9779):1778-97. https://doi.org/10.1016/So 140-6736(11)60054-8

[27] Nascimento AC, Moysés ST, Werneck RI, Moysés SJ. Oral health in the context of primary care in Brazil. Int Dent J 2013; 63(5):237-43. https://doi.org/10.1111/idj.12039

[28] Baldani MH, Antunes JL. Inequalities in access and utilization of dental services: a cross-sectional study in an area covered by the Family Health Strategy. Cad Saúde Pública 2011; 27:272-83. https://doi.org/10.1590/s0102-311x2011001400014

[29] Kidd E, Fejerskov O. Changing concepts in cariology: Forty years on. Dent Update 2013; 40(4):277-86. https://doi.org/10.12968/denu.2013.40.4.277 
[30] Antunes JL, Peres MA, de Campos Mello TR, Waldman EA. Multilevel assessment of determinants of dental caries experience in Brazil. Community Dent Oral Epidemiol 2006; 34(2):146-52. https://doi.org/10.1111/j.1600-0528.2006.00274.x

[31] Miyazaki H, Pilot T, Leclercq MH, WHO Oral Health Programme. Periodontal profiles: an overview of CPITN data in the WHO global oral data bank for the age groups 15-19 years and 35-44 years as of 1 August 1990 / Hideo Miyazaki, Taco Pilot, Marie-Hélène Leclercq. World Health Organization. 1990. Available from: https://apps.who.int/iris/handle/10665/61678. [Accessed on June 22, 2016].

[32] Tonetti MS, Chapple ILC, Jepsen S, Sanz M. Primary and secondary prevention of periodontal and peri-implant diseases-Introduction to, and objectives of the 11 th European workshop on periodontology consensus conference. J Clin Periodontol 2015; 42:1-4. https://doi.org/10.1111/jcpe.12382 